\title{
Potential activity of Linezolid against SARS-CoV-2 using electronic and molecular docking study
}

\author{
Nelson H. Morgon ${ }^{1}$. Giulia S. Grandini ${ }^{2}$ Maurício I. Yoguim ${ }^{2}$ - Caio M. Porto ${ }^{1}$ - Lucas C. Santana ${ }^{1}$. Srijit Biswas ${ }^{3}$. \\ Aguinaldo R. de Souza ${ }^{2}$
}

Received: 30 March 2021 / Accepted: 16 June 2021 / Published online: 8 July 2021

(C) The Author(s), under exclusive licence to Springer-Verlag GmbH Germany, part of Springer Nature 2021

\begin{abstract}
The crescent evolution of a global pandemic COVID-19 and its respiratory syndrome (SARS-Cov-2) has been a constant concern (Ghosh 2021; Khan et al. 2021; Alazmi and Motwalli 2020; Vargas et al. 2020). The absence of a proven and effective medication has compelled all the scientific community to search for a new drug. The use of known drugs is a faster way to develop new therapies. Molecular docking is a powerful tool (Gao et al. J Mol Model 10: 44-54, 2004; Singh et al. J Mol Model 18: 39-51, 2012; Schulz-Gasch and Stahl J Mol Model 9:47-57, 2003) to study the interaction of potential drugs with SARS-CoV-2, Alsalme et al. (2020) and Sanders et al. (2020) spike protein as a consequence the main goal of this article is to present the result of the study of an interaction between $(R$ and $S$ )-Linezolid with receptor-binding domain (RBD) of SARS-Cov-2 spike protein complexed with human Angiostensin-converting enzyme 2 (ACE2) (6vW1 - from PDB). The Linezolid enantiomers were optimized at B3LYP/6-311++G(2d,p) level of theory. Molecular docking of the system $(S)$-Linezolid $\cdots$ RBD $\cdots$ ACE2 and $(R)$-Linezolid $\cdots$ RBD $\cdots$ ACE2 was performed, the analysis was made using LigPlot+ and NCIplot software packages, to understand the intermolecular interactions. The UV-Vis and ECD of the complexes - $(R$ and $S)$-Linezolid $\cdots$ RBD $\cdots$ ACE2 were performed in two layers with DFT/6-311++G(3df,2p) and DFT/6$31 \mathrm{G}(\mathrm{d})$, respectively. The results showed that only the $(S)$-Linezolid had a stable interaction with $-8.05 \mathrm{kcal}^{\mathrm{mol}}{ }^{-1}$, whereas all the $R$-enantiomeric configurations had positive values of binding energy. The ( $S$ )-Linezolid had the same interactions as in the $(S)$-Linezolid … Haluarcula morismortui Ribosomal system, where it is well-known the fact that the latter has biological activity. A specific interaction on the fluorine ring justified an attenuation on the ECD signal, in comparison to isolated species. Therefore, some biological activity of (S)-Linezolid with SARS-CoV-2 RBD was expected, indicated by the modification of its ECD signal and justified by a similar interaction in the $S$-Linezolid $\cdots$ Haluarcula marismortui Ribosomal system.
\end{abstract}

Keywords Linezolid $\cdot$ SARS-CoV-2 $\cdot$ Molecular docking

This paper belongs to the Topical Collection VIII Symposium on Electronic Structure and Molecular Dynamics - VIII SeedMol

Nelson H. Morgon

nhmorgon@unicamp.br

1 Department of Physical Chemistry, Campinas State University, Institute of Chemistry, Campinas, São Paulo, 13083-970, Brazil

2 School of Science, Department of Chemistry, São Paulo State University, Bauru, São Paulo, 17033-360, Brazil

3 Department of Chemistry, University of Calcutta, 92, A.P.C. Road, Kolkata, 700009, India

\section{Introduction}

The global pandemic COVID-19 is caused by the acute respiratory syndrome (SARS-Cov-2). Up to the present date, March 25, 2021, the number of infected people around the world is $124,535,520$ with 2,738,876 confirmed deaths [10]. Yet, no medical treatment is known to bring real and effective improvement over the condition of patients afflicted with COVID-19. However, some drugs have shown in vitro activity against SARS-Cov-2, or some clinical benefit in non-randomized trials till date [11]. Redemsivir (an antiviral) and Moxifloxacin (an antibiotic 
[12]) have been used for COVID-19 patients in clinical trials or clinically in emergency conditions [13, 14], where the first drug has been shown to be active in the RNA-dependent RNA polymerase $(\operatorname{RdRp})$ bond [15, 16]. The most used drugs to treat this disease are antivirals, antibiotics, corticosteroids, and immunoglobulins [17, 18]. They have displayed some effectiveness in randomized trials, but a potent drug is still nowhere in sight.

The fast development of new therapeutic drugs that can target SARS-Cov-2 indicates that the scientific community seeks treatment and potential cure for the COVID-19 patients. One of the drug classes that are widely used against COVID-19 are antibiotics. The combination of methodologies based in drug design, molecular docking, and electronic structure methods can be a helping hand in the search for effective drugs against SARS-Cov-2 and treatment strategies [19-24]. In a recent editorial published by the World Health Organization (WHO), caution is recommended when treating COVID-19 patients using antibiotics. At the same editorial, an alert is raised for the adoption of an integrated approach in the use of antibiotics, as for example refraining from prescribing antibiotics for patients with a mild to moderate COVID-19 case unless the patient has a bacterial infection [25]. Activities that require the prescription of antibiotics should be integrated with the pandemic and the healthcare system. This integration is achieved through five steps which involve the clinical competence of the health workers that treat patients suffering from COVID-19, as for example the identification of the signs and symptoms associated with fungal and bacterial diseases and the implementation of researches that ensure that antibiotics prescription activities become an integral part in the hunt for effective and safe therapies against the pandemic. Although the vaccine is already in development and use in some age groups, there are treatments being tested involving a range of drugs such as antibiotics and antivirals. One of the mechanisms widely studied in the invasion of the virus to the organism is the formation of the spike protein complex of SARS-CoV-2 with the human enzyme ACE2. The interest of this complex is in the fact that spike protein from SARS-CoV- 2 has more affinity with ACE2 than spike protein from SARS-CoV [26]. The computational approach has been extensively explored in studies of possible drugs against infection by SARSCoV-2. Sagaama et al. [27] presented results of possible drugs complexed with SARS-CoV-2 proteins using theoretical level DFT and Molecular Docking as well as Jordaan et al. [28] with results involving Simvastatin, Lovastatin, Oxacilin, podophyllotoxin, gefitinib with SARSCoV-2 main protease. As a consequence, the main goal of this article is to present the result of the study of an interaction between ( $R$ and $S$ )-Linezolid with RBD of SARS-CoV-2 spike protein in complex with human ACE2. Linezolid is the first agent of a new class of antibiotics called the oxazolidinones ([29], [30], [31]) which represent the first truly new class of antibacterial agents to reach the marketplace in several decades [32].

\section{Methods}

\section{Molecular structures}

Conformational analysis was computed using a relaxed scanning of the potential energy surface (PES) for $(R$ and $S$ )Linezolid. The procedure involved a simultaneous relaxed scanning of all five dihedral angles (Fig. 1). The calculations were carried out at every $60^{\circ}$ interval in the range $0-360^{\circ}$ at the semiempirical method (PM6). This level was chosen due to the very large number of PES points involved, 7776 calculations for each enantiomer.

The conformational population was calculated based on the Boltzmann distribution (1) considering PM6 electronic energies. To the five most stable molecular structures for $(R$ and $S$ )-Linezolid, according to statistical thermodynamic analysis, the molecular geometries were re-optimized at B3LYP/6-311++G(2d,p) level of theory. The vibrational frequency analyses on the same level were performed for these compounds. The computed vibration frequencies contained no imaginary frequencies, which indicates that the optimized geometries are local minima at the PES.

$$
P_{i}(\%)=\frac{e^{-\Delta G_{i} / R T}}{\sum_{i=1}^{N} e^{-\Delta G_{i} / R T}}
$$

where $\mathrm{P}_{i}$ and $\mathrm{G}_{i}$ are the fractional population and Gibbs free energy of the $\mathrm{i}$-th conformer at $298.15 \mathrm{~K}$ of temperature and $1.00 \mathrm{~atm}$ of pressure.

Figure $2 \mathrm{a}$ represents the protein-ligand docking. In other words, the interacting amino acids residues present in the binding site and the ligand (S)-Linezolid. In Fig. 2b, the

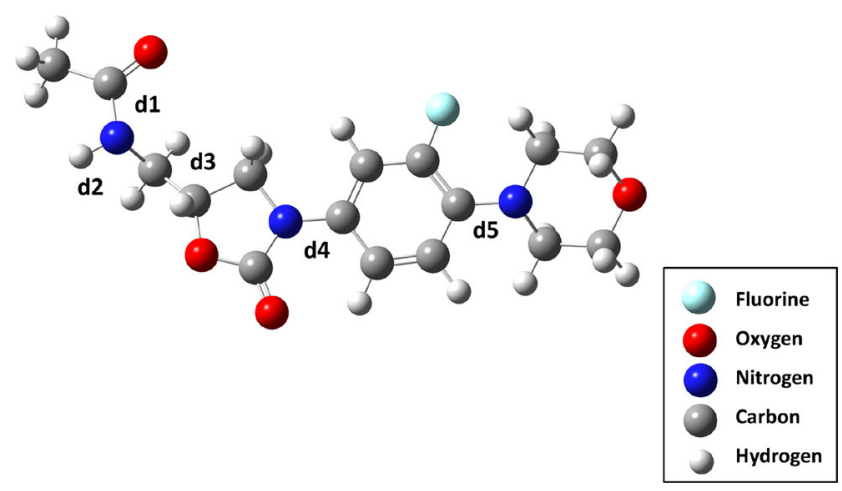

Fig. 1 Dihedral angles employed at PM6 PES scan of conformation $(R$ and $S$ )-Linezolid 

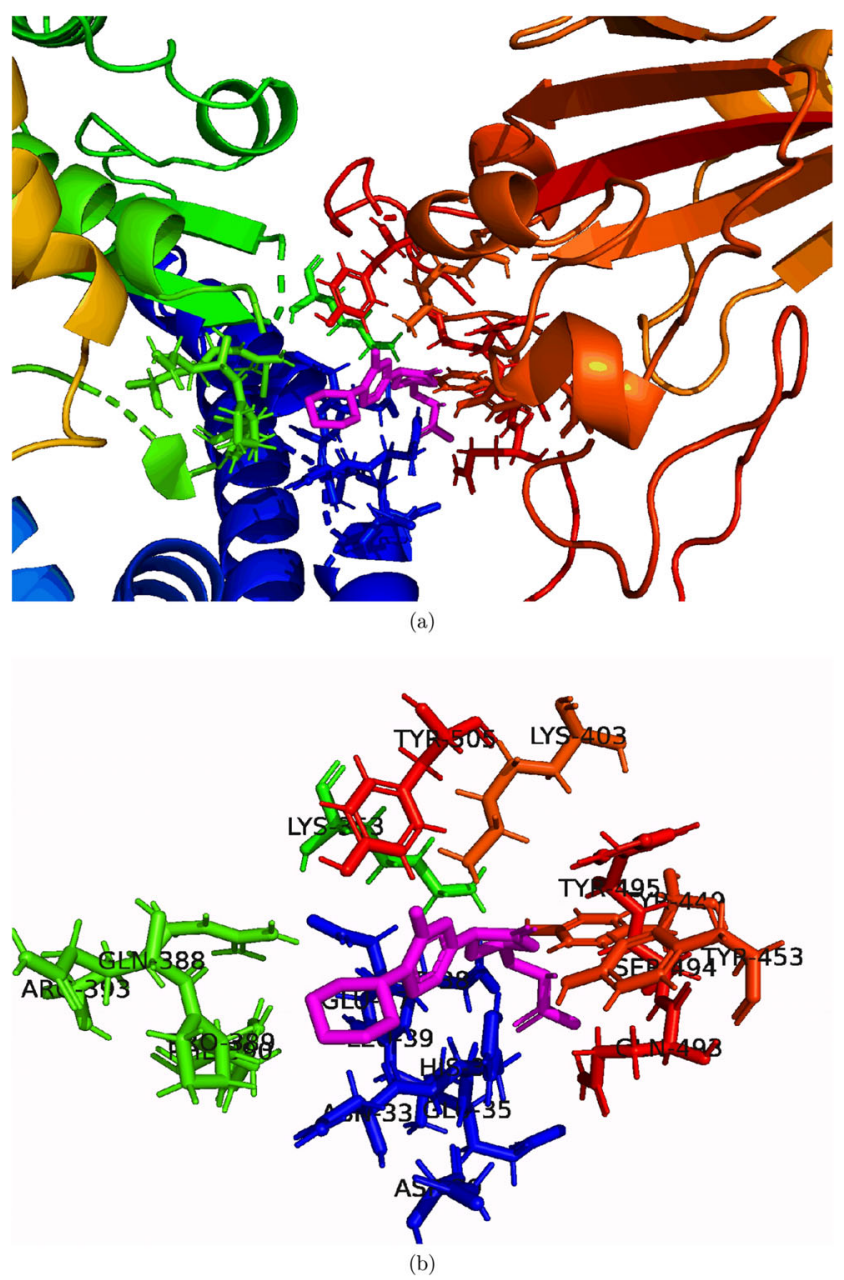

Fig. 2 (a) Molecular systems based on protein and ligand complex. (b) The binding site and the $(S)$-Linezolid complex was defined considering a neighborhood of $3.0 \AA$. In this theoretical system ONIOM (QM:QM) calculations were employed, where the atoms at the high level are in dark blue (ligand) and binding site represents the outer layer

complex can be observed, considering a neighborhood of $3.0 \AA$ Abtained from the center of mass of ligand.

The molecular system, binding site and $(S)$-Linezolid, was represented by two layers, described by different computational methodologies using the ONIOM approach. In this computational approach, the molecular system has been represented by an inner (Linezolid ligand) and an outer layer (Binding Site), described by different computational methodologies (Fig. 2a and b, respectively). In the two-layered ONIOM method, the inner layer is termed "model" and is treated with both the low and high levels of theory. In this manuscript, both layers were described by DFT or TD-DFT levels of theory. The high and lower levels were represented by the methods DFT/6-311++G(3df,2p) and DFT/6-31G(d), respectively. The B3LYP and PBE0 functionals were employed, which are both hybrid exchange-correlation functionals.
Hydrogen atoms were added to fill the valences. The positions of these atoms were optimized at ONIOM(B3LYP:B3LYP) method, while the position of the remaining atoms was frozen using structural parameters taken from the docking calculation.

\section{Electronic spectra: UV-Vis and CD}

Theoretical investigations of excited states (UV-Vis and ECD), to simulate the shape of absorption and emission spectra, have been carried out employing TD-DFT along the D3 version of Grimme's dispersion with Becke-Johnson damping [33].

The electronic spectra of all structures were obtained using the TD-DFT or ONIOM approaches (TD-DFT:TDDFT). In all calculations, singlet ground states and thirty electronic states were considered. The molecular structures of ( $R$ and $S$ )-Linezolid and binding site of Ribosomal bacteria Haluarcula marismortui [34] with (S)Linezolid were calculated were calculated at (PBE0/6$311++\mathrm{G}(3 \mathrm{df}, 2 \mathrm{p}) / / \mathrm{B} 3 \mathrm{LYP} / 6-311++\mathrm{G}(2 \mathrm{~d}, \mathrm{p})+\mathrm{GD} 3 \mathrm{BJ})$ and (TD-DFT (PBE0/6-311++G(3df,2p): PBE0/6-31G(d) + GD3BJ) high levels of theory, respectively.

ECD is an extremely powerful method for exploration of chirality and stereoselectivity of inorganic and organic molecules and is based on differential absorption by a chiral molecule of left and right circularly polarized light in the UV and visible regions [35]. The simulated ECD spectra have been obtained as the combination of the bands computed through theoretical calculations (such as for example TD-DFT). ECD signals for molar absorptivity and intensity are theoretically related to $\Delta \epsilon$ (2) and rotatory strength $\left(R_{0 \rightarrow i}\right)$ quantities (3), respectively. In Eq. 2, $\epsilon_{l}$ and $\epsilon_{r}$ are the molar absorptivity coefficients for the left and right circularly polarized light, respectively, $c$ is the molar concentration and $b$ the path length.

$\Delta \epsilon=\frac{\epsilon_{l}-\epsilon_{r}}{c b}$

The intensity of an absorption band associated with the transition between $\left|\Psi_{0}\right\rangle$ and $\left|\Psi_{i}\right\rangle$ can be related to the rotatory strength:

$R_{0 \rightarrow i}=\Im\left(\mu_{0 \rightarrow i} \cdot m_{0 \rightarrow i}\right)$

where $\mu_{0 \rightarrow i}=\int \Psi_{i}^{*}(\vec{r}) \hat{\mu} \Psi_{0}(\vec{r}) d \vec{r}$ and $m_{0 \rightarrow i}=$ $\int \Psi_{i}^{*}(\vec{r}) \hat{m} \Psi_{0}(\vec{r}) d \vec{r}$, i.e., the imaginary component of the scalar product between the electric and magnetic moments. In the case of the CD spectrum, the PBE0 functional has produced the best result when compared to the experimental results [35].

All calculations were performed using Gaussian program [36]. 


\section{Molecular docking}

To be able to study the protein and ligand, their structures were needed. In the case of the ligand $R$ and $S$ linezolid, their structures were built in Gaussview [37], following the structures available in PubChem [38]. The protein structure was obtained from the Protein Data Bank (PDB) [39]. Using the report of Ahmed et al. [40] as support, the proteic structure was chosen among the crystalline representations of RBD SARS-CoV-2 spike protein with the human protein. The PDB code for this structure is 6vw1 [41], and it has a resolution of $2.68 \AA$. The docking methodology the molecular structure of the protein is treated as rigid, while the structures of the ligand $((R)$ - or $(S)$-Linezolid) are kept flexible to achieve the best fit conformation (ligand-receptor complex). In this work, the Autodock software was used to carry out molecular docking studies [42]. The calculations to obtain the corresponding energy values as ligand poses are based on Monte Carlo algorithms [43].

The selection of the studied location for molecular docking in this software is made through the box parameters. The ones used in the present work were of $10 \AA$ in the $x, y$, and $z$ directions, with $1.0 \AA$ spacing. The coordinates used were $-15.083(x),-21.056(y)$, and $7.75(z)$. The software generates 100 structural conformers (poses) of the ligand under study, and gives each pose a respective energy value which is based on the equation:

$\Delta G_{\text {binding }}=\Delta G_{\text {complex }}-\Delta G_{\text {receptor }}-\Delta G_{\text {inhibitor }}$

In (4), each of the terms involves the calculation of various energy components such as the following: van der Waals energy, electrostauic energy, and internal plus molecular mechanism. There are also polar and non-polar contributions to the solvation energy, and the entropy of the inhibitor. The results obtained through the docking were analyzed in relation to the energy, in order to obtain the minimum energy structure. Next, the interaction studies of the ligand in the proteins were done with the Discovery Studio Visualizer 2019 (DS)[44] and LigPlot+ software programs [45].

\section{Non-covalent interactions}

The non-convalent interactions (NCI) between the ligands and proteins were investigated using the NCIPLOT software [46]. The method is based on the analysis of $\rho(r)$, the electron densities, and $s(\rho)$, the reduced density gradient (RDG). The 2D graph of $\rho(r)$ versus $s(\rho)$ between two interacting molecules shows density critical points that are absent when there is no interaction between them. In these critical points, the Laplacian of $\rho(r)$ dominates so the RDG tends to zero. Contreras-García et al [47] The strategy is to search for these critical points and build the volumes of non-covalent interactions. The differentiation between attractive and repulsive interactions is made by the sign of the second eigenvalue of the electron density Hessian $\lambda$. For attractive interactions as hydrogen bonds, the sign of $\lambda_{2}$ is negative while for repulsive interactions as steric crowding, the sign of $\lambda_{2}$ is positive. Weak interactions have a density overlap close to zero, so $\lambda_{2}$ is approximately zero, which is the case for van der Waals interactions and weak repulsive interactions. The interactions were analyzed with $\mathrm{s}=0.4$ au and either applying two color range, one of -0.01 to 0.01 , indicating attractive (blue) and repulsive (red) interactions only, or applying a color range of -4.00 to 4.00 , indicating attractive (blue), repulsive (red), and weak (green) interactions.

\section{Results and discussion}

\section{Molecular structures}

The Gibbs free energies for stable conformers obtained from conformational analyses are listed at Table 1 .

\section{Electronic spectra: UV-Vis and CD}

The UV-Vis and CD electronic spectra of the molecular systems, $(R$ and $S)$-Linezolid and both binding site with $(S)$ Linezolid, are given in Fig. 3a and b, respectively. In the case of the UV-Vis spectrum of the Linezolid, we observe two characteristic transitions: one due to the lone-pair of the nitrogen atom (in the acyl-amino methyl group) at $\approx$

Table 1 Energies (in hartree) of the five most stable molecular structures for $(R$ and $R$ )-Linezolid and Boltzmann population (\%)

\begin{tabular}{lllll}
\hline Enantiomers & $\mathrm{EE}^{(a)}$ & $\mathrm{TMG}^{(b)}$ & $\mathrm{GFE}$ & \\
\hline $\mathrm{R}(1)$ & -1185.90268 & 0.30246 & -1185.60022 & 0.15 \\
$\mathrm{R}(2)$ & -1185.90689 & 0.30376 & -1185.60313 & 3.19 \\
$\mathrm{R}(3)$ & -1185.90507 & 0.30120 & -1185.60387 & 6.99 \\
$\mathrm{R}(4)$ & -1185.90511 & 0.30006 & -1185.60505 & 24.38 \\
$\mathrm{R}(5)$ & -1185.90897 & 0.30299 & -1185.60598 & 65.29 \\
$\mathrm{~S}(1)$ & -1185.89829 & 0.30661 & -1185.59168 & 0.01 \\
$\mathrm{~S}(2)$ & -1185.90543 & 0.30453 & -1185.60090 & 0.08 \\
$\mathrm{~S}(3)$ & -1185.90500 & 0.30091 & -1185.60409 & 2.44 \\
$\mathrm{~S}(4)$ & -1185.90864 & 0.30192 & -1185.60672 & 39.55 \\
$\mathrm{~S}(5)$ & -1185.90859 & 0.30151 & -1185.60708 & 57.92 \\
\hline
\end{tabular}

${ }^{a}$ Electronic Energy calculated at PBE0/6-311++G(3df,2p)// B3LYP/6$311++\mathrm{G}(2 \mathrm{~d}, \mathrm{p})$

${ }^{\mathrm{b}}$ Thermal correction to Gibbs Free Energy obtained at B3LYP/6$311++\mathrm{G}(2 \mathrm{~d}, \mathrm{p})$

${ }^{\mathrm{c}}$ Sum of electronic and thermal free energies, using $298.15 \mathrm{~K}$ and $1.00 \mathrm{~atm}$ 
Fig. 3 Theoretical electronic spectra of the molecular systems $(R$ and $S$ )-Linezolid and both binding site containing $(S)$-Linezolid

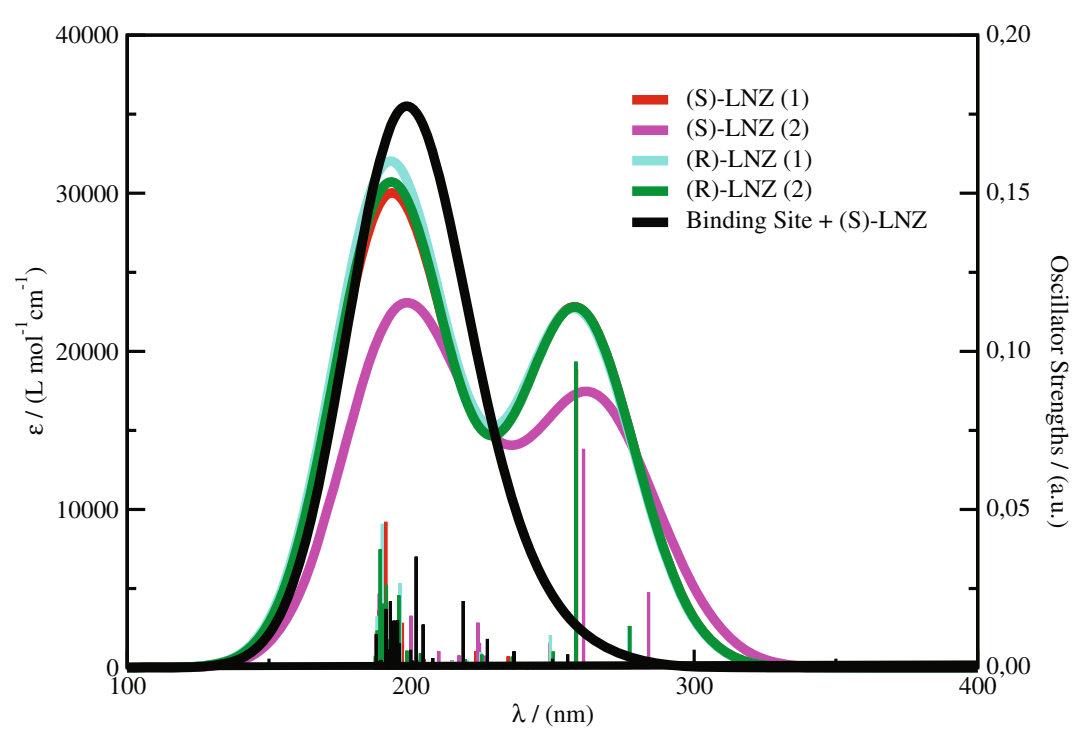

(a) UV-Vis

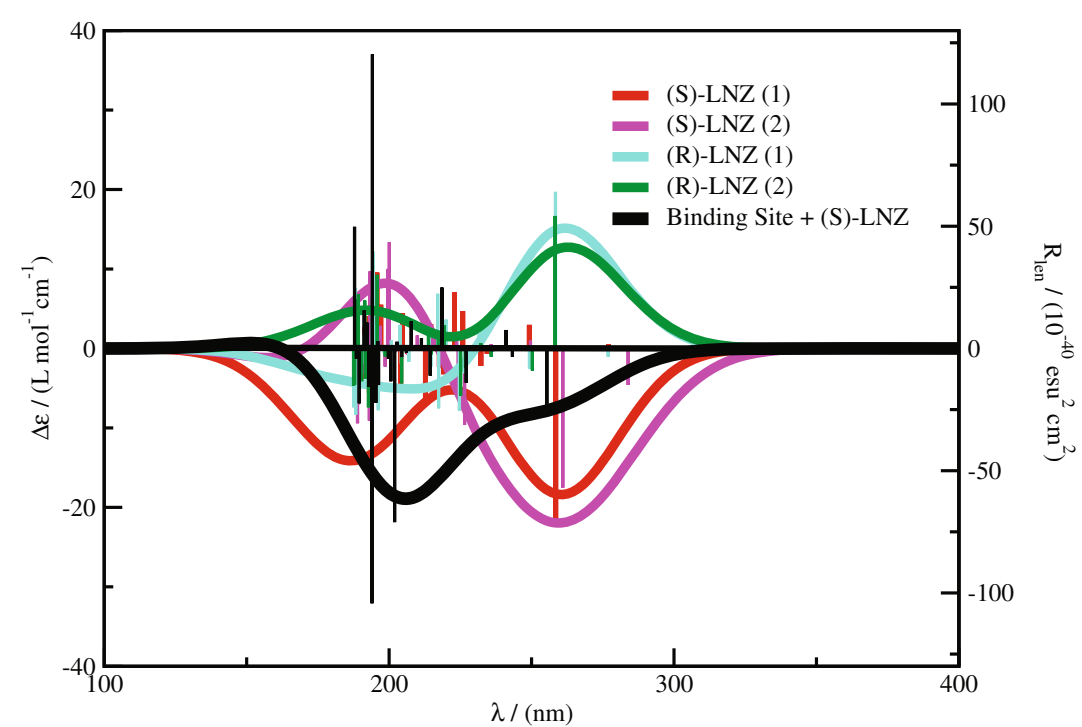

(b) ECD
$260 \mathrm{~nm}$ and the other due to the carbon chain located at $\approx 180 \mathrm{~nm}$. The first electronic transition $(n \rightarrow \pi)$ present in the isolated ligand disappears in the proteinligand system, due to the interaction between the residues HIS34 and GLU37 and the oxazolidone. The LUMO of the Linezolid is on the oxazolidinone moiety, as shown previously, so the interaction between it and the amino acids makes these orbitals less available for the excitation. This happens possibly via donation electron density from the residues to the to the oxazolidinone.

The electronic transitions located at a wavelength $\approx$ $260 \mathrm{~nm}$, observed in the ( $R$ and $S$ )-Linezolid, are associated with the HOMO molecular orbital located at the nitrogen atom (in acyl-amino methyl group) and the LUMO and
LUMO+1 orbitals distributed through the aromatic chain, as can be seen in Fig. $4 \mathrm{a}$ - c, respectively.

Linezolid is a chiral object due to its molecular structure. The chiral environment is well expressed in two portions of the molecule: in $C^{*} 5-(R$ or $S)$ - configuration and in $\mathrm{N}^{*}$ atom localized on the acyl-amino-methyl group. The ECD signal associated with $\mathrm{C}^{*}$ appears at $\approx 180 \mathrm{~nm}$, while the one due to the $\mathrm{N}^{*}$ appears at $\approx 260 \mathrm{~nm}$. We can observe in Fig. $3 \mathrm{~b}$ the behavior of the ECD considering these chiral environments. The Cotton effects found for such compounds are well pronounced. In the complex (binding site containing $S$ Linezolid) the interaction between the oxazolidinone and amino acid residues HIS34 and GLU37 attenuates the ECD signal, similarly as it was seen for the UV-Vis analysis. 
Fig. 4 Electronic transitions associated at molecular orbitals: (a) HOMO localized at the nitrogen atom (in acyl-amino methyl group), and (b) LUMO and (c) LUMO+1 distributed in the aromatic chain, $n \rightarrow \pi$ and $n \rightarrow \pi^{*}$, respectively

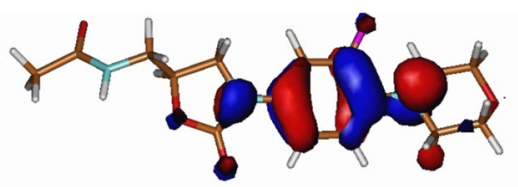

(a) $\mathrm{HOMO}$

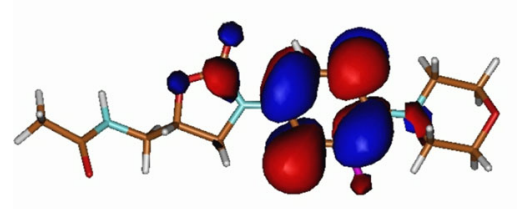

(b) LUMO

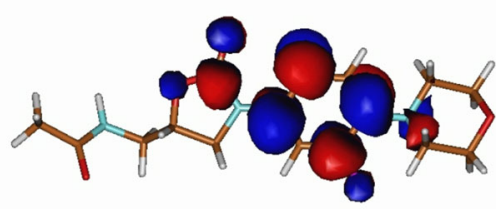

(c) $\mathrm{LUMO}+1$
In the isolated ligand, the maximum absorption due to the $\mathrm{C}^{*} 5-(S)$ - configuration is at $189 \mathrm{~nm}$, but in the complex it is present at a longer wavelength, $192 \mathrm{~nm}$. This bathochromic shift occurs because of a change in the environmental condition, that is, the binding site is a polar environment.

\section{Molecular docking}

In the $(R)$-Linezolid with RBD SARS-CoV-2 spike protein with the human protein ACE2 (6vW1 - PDB), molecular docking all configurations resulted in a positive interaction energy. The most stable configuration produced a binding energy of $+69,6 \mathrm{kcal}^{\mathrm{mol}}{ }^{-1}$. Therefore, the $(R)$-Linezolid did not displayed high affinity in the protein region. The $(S)$-Linezolid structure, however, produced a very different result than the ones from the $(R)$-Linezolid. In the same region, the $(S)$-Linezolid resulted in a stabilization energy of $-8.05 \mathrm{kcal} . \mathrm{mol}^{-1}$. In general, the $\mathrm{S}$ structure gave a number of conformational structures and sites that provided low energy. Figure 5 presents the interaction of Linezolid enantiomers with RBD SARS-CoV-2 spike protein complexed with human ACE2. The relation of configuration and their energy bindings is found on Fig. S1 in the Supporting Material.

As can be noticed from Fig. 5, the most stable locations for the $(S)$-Linezolid and the $(R)$-Linezolid are in the same region, which is formed by the docking cavity distant approximately $7.68 \AA$. All other possible positions resulted in higher energy values However, the $S$ structure is stable and has a negative energy value for the interaction with the protein, while the $R$ structure energy is extremely positive. This is why we believe that $(S)$-Linezolid provides a biological activity and the $(R)$-Linezolid does not provide this property. As it is well-known, the $(R)$-enantiomers of all oxazolidinones are devoid of antibiotics properties. Brickner [48] Haluarcula marismortui Ribosomal ...(S)Linezolid system is stable and has biological activity. Ippolito et al. [34] The results obtained on the DS software show that there are three hydrogen bond interactions between the $(S)$-Linezolid and the LYS403, TYR453, and SER494 SARS-CoV-2 amino acids (Fig. S2 in the Supporting Material). This interactions have a distance of $2.57 \AA, 2.70 \AA$ and $1.94 \AA$, respectively. At the same time, eight hydrophobic can be seen. From these, two from the GLU37, from the human protein, and one from TYR495, from SARS-CoV-2, are of the type $\sigma-\sigma$. There is also an interaction of the type $\pi-\sigma$ with the amino acid GLU37 and two interactions of the type $\pi-\pi$ with HIS34, both residues being from the human protein.

The results from LigPlot+ software are presented in Fig. 6. It can be noticed that the hydrogen bond interactions
Fig. 5 The molecular docking (PDB:6vw1) representation of the most stable interaction locations between $(R)$ and $(S)$-Linezolid with SARS-CoV-2 RBD spike protein, from molecular docking

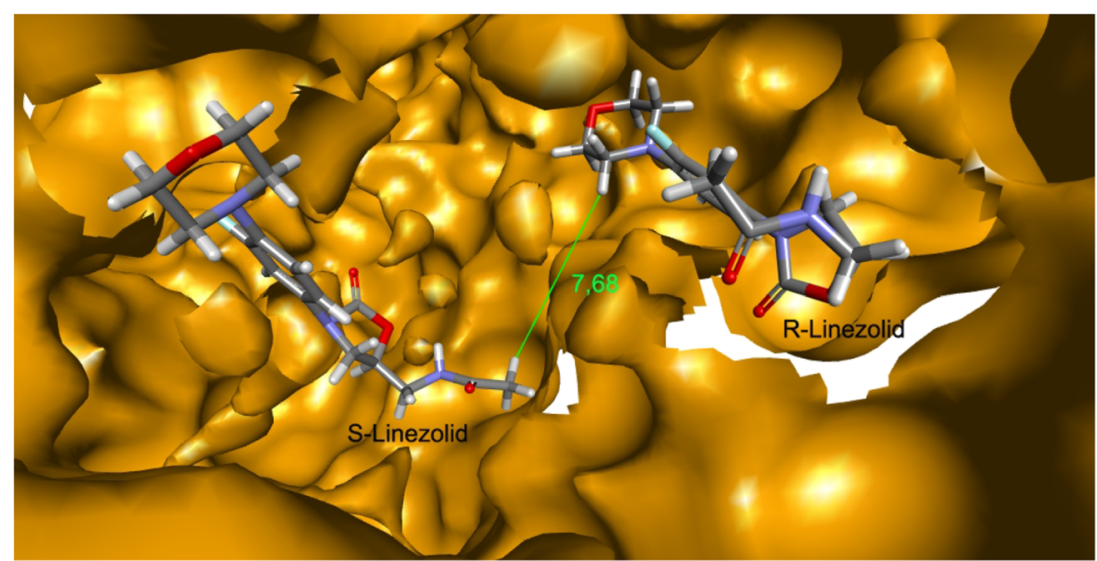


Fig. 6 Representation of interaction sites of

(S)-Linezolid $\cdots H$. marismortui Ribosomal (a) and

(S)-Linezolid . RBD ‥ ACE2

(b)

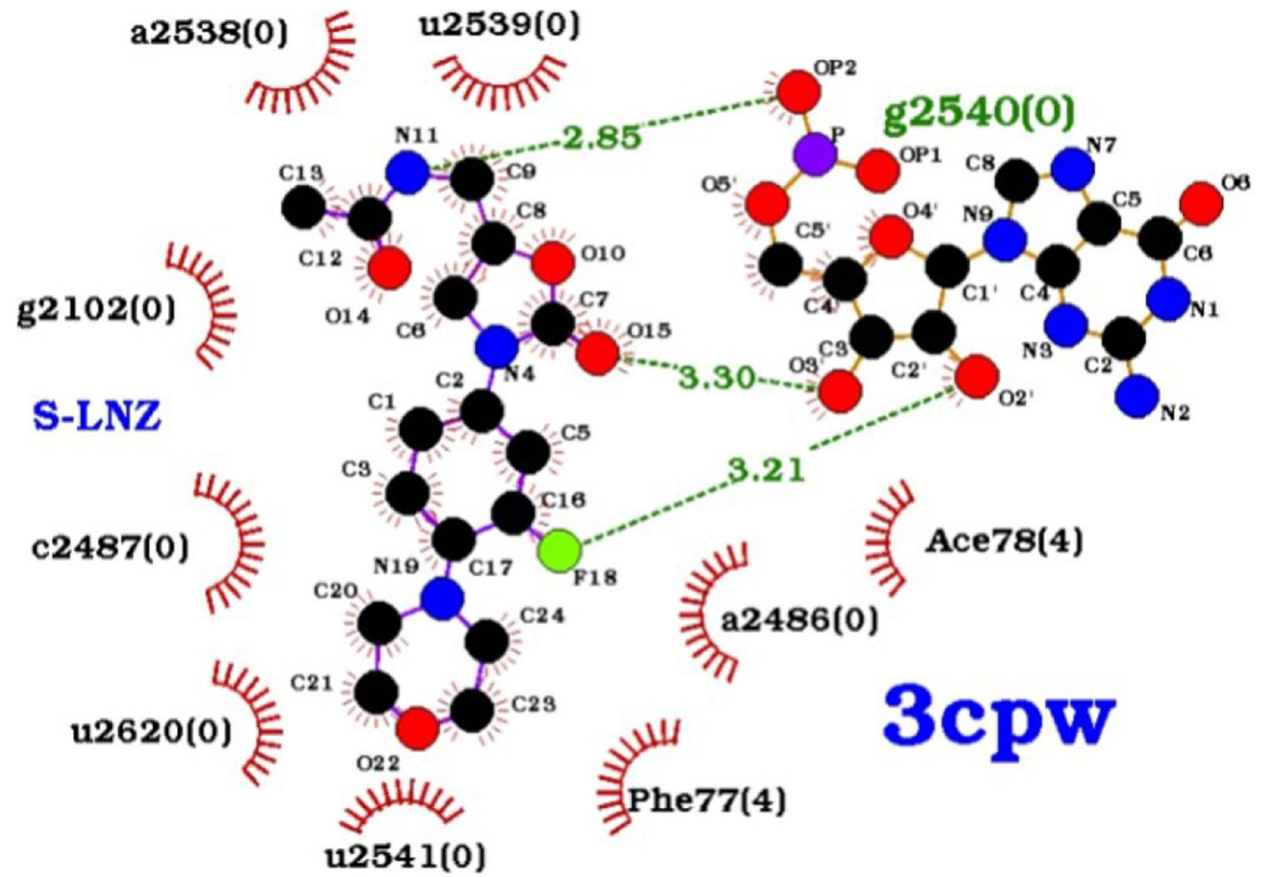

(a)

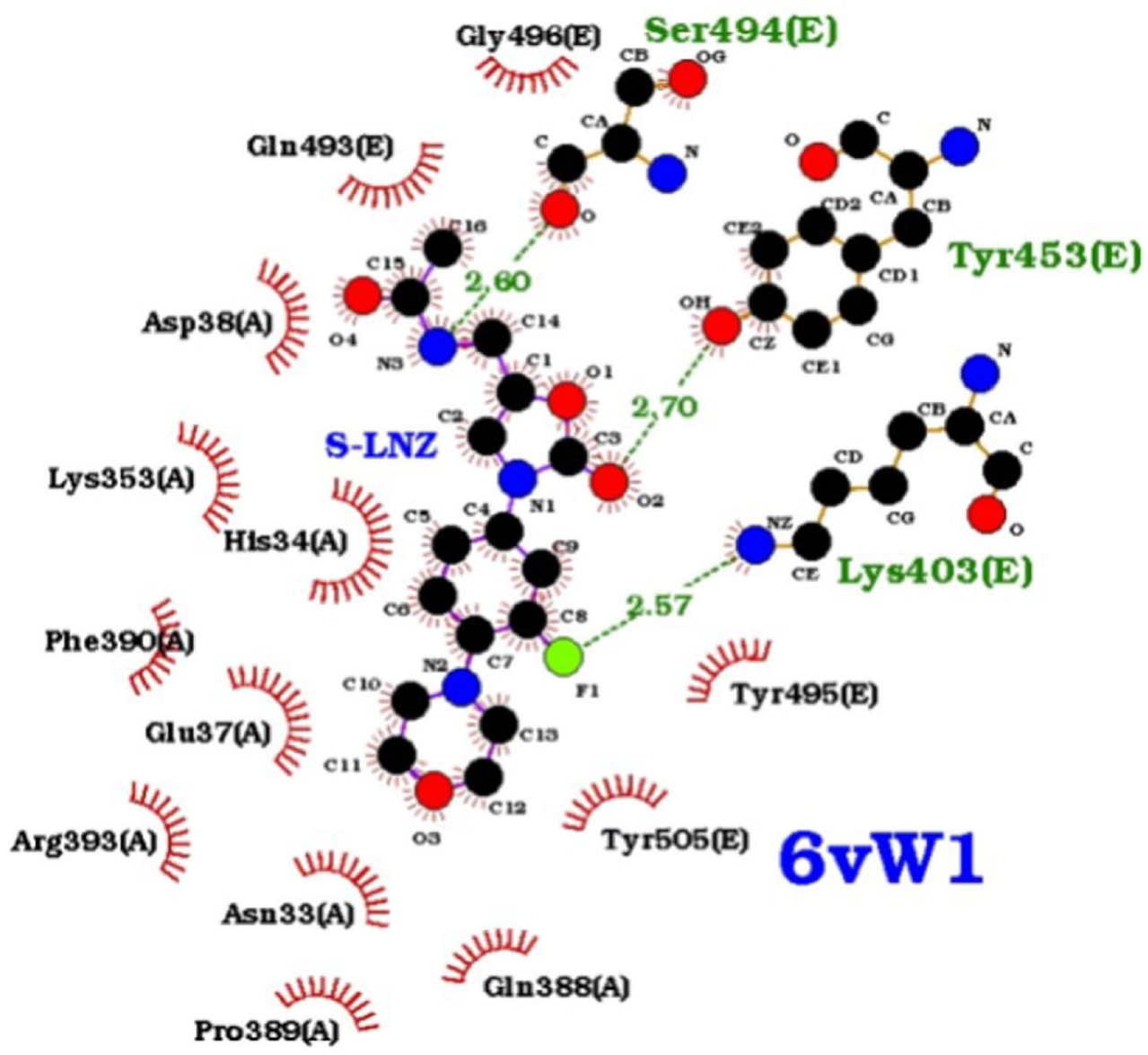

(b) 
are the same as the ones obtained from the DS software analysis, namely three hydrogen bonds with residues LYS 403, TYR453, and SER494. The only difference is that the distance from the ligand to the residue SER494 that went from $1.94 \AA$ (DS) to $2.60 \AA$. In the case of the hydrophobic interactions, the analysis shows that there are thirteen of them, nine being from the human protein structure (ASN33, HIS34, GLU37, ASP38, LYS353, GLN388, PRO389, PHE390, and ARG393) and four being from the
SARS-CoV-2 RBD spike protein (6vW1 - PDB) structure (GLN493, TYR495, GLY496, and TYR505). For the $(R)-$ Linezolid LigPlot+, Fig. S3, none of the hydrogen bonds present between the $\mathrm{S}$ enantiomer and both the protein spike of Sars-Cov-2 RBD spike protein (6vW1 - PDB) and $H$. marismortui Ribosomal protein, are present. There was a hydrogen bond interaction between the $\mathrm{O}$ atom of the $\mathrm{C}$ 5-acyl-amino-methyl moiety and GLN76 residue, with a distance of $2.93 \AA \AA$.
Fig. 7 Representation of the interaction surface between (a) (S)-Linezolid with $H$. marismortui Ribosomal and (b) SARS-CoV-2 RBD spike protein structure. The isovalue was 0.4 au with a color range of -0.01 to 0.01 , so blue represents an attractive interaction and red represents a repulsive one

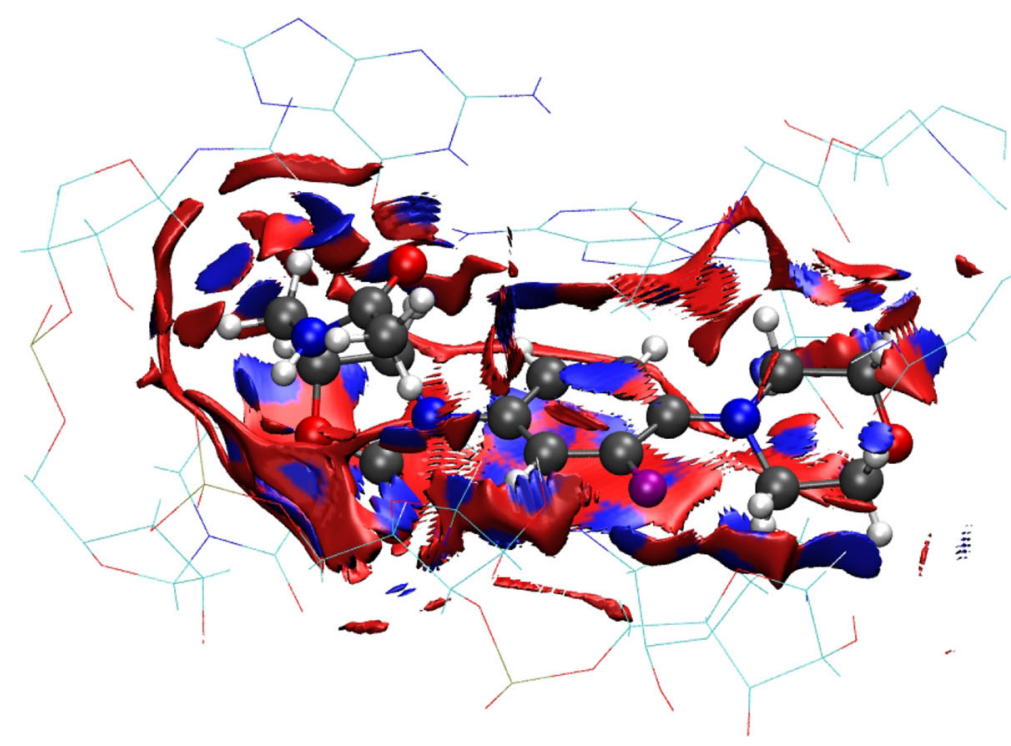

(a)

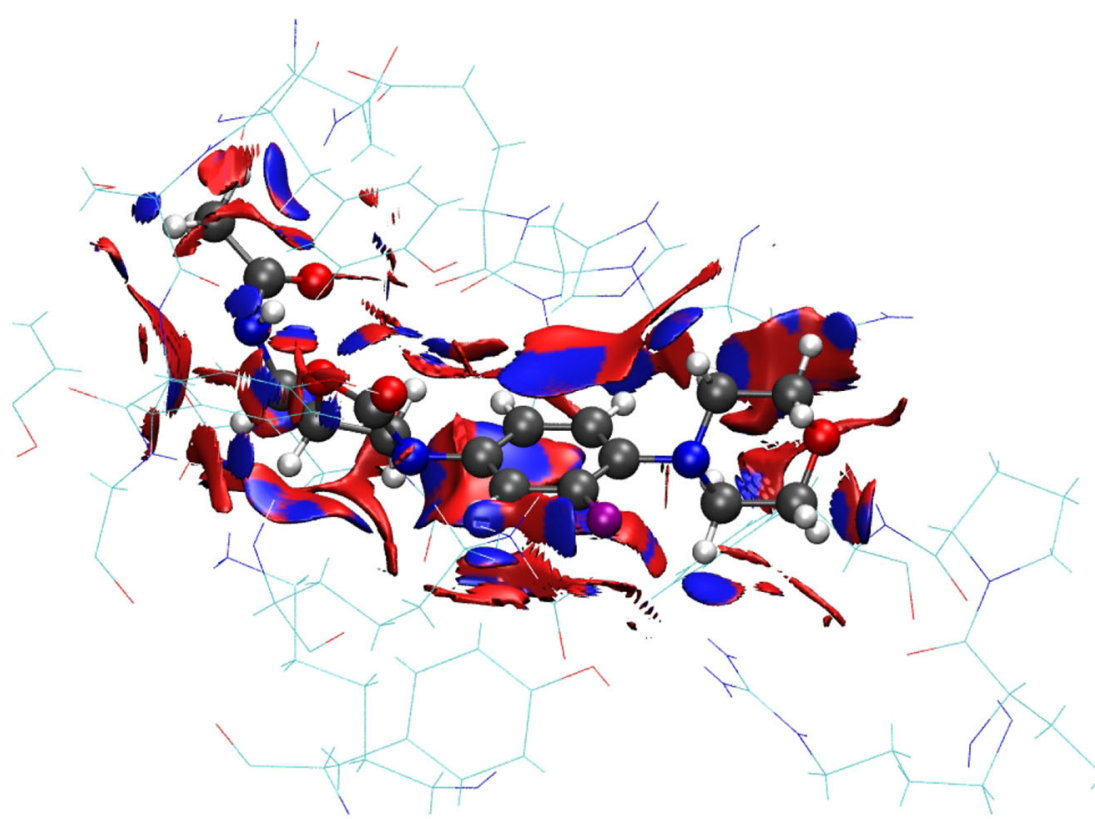

(b) 


\section{Non-covalent interactions}

The ability of $(S)$-Linezolid to favorably interact with the SARS-CoV-2 spike protein ((S)Linezolid...RBD...ACE2) can be justified by similar interactions seen of the first with Haluarcula marismortui, a bacteria, Ribosomal unit $((S)$-Linezolid $\cdots$ Ribosomal), as show on Fig. 6. Three hydrogen interactions could be seen in both the Haluarcula morismortui Ribosomal and RBD . . ACE2 complex. The first interaction is of the N atom in C-5-acyl-amino-methyl group on $(S)$-Linezolid, which has an interaction with Ribosomal close to $2.85 \AA$. The same $\mathrm{N}$ atom presents an interaction close to $2.85 \AA$ with the Ser494 amino acid of SARS-CoV-2. The second interaction was from the oxygen atom of oxazolidone, which had a distance of $3.3 \AA$ with the Ribosomal and $2.7 \AA$ with the Tyr453 amino acid of SARS-CoV-2. The third interaction was from the Florine atom of $(S)$ Linezolid, which had a distance of $3.21 \AA$ from the Ribosomal and $2.57 \AA$ to Lys403 amino acid fo SARSCoV-2. The $(S)$-Linezolid . . RBD …ACE2 has a shorter interaction distance than (S)-Linezolid...Haluarcula morismortui Ribosomal, suggesting that the interactions with SARS-CoV-2 protein are stable.

All interactions between $(S)$-Linezolid $\cdots$ Ribosomal and $(S)$-Linezolid . . RBD … ACE2 are easy to see by attractive and negative surface interaction by NCIplot, Fig. 7.

Fig. 8 Non-covalent interactions for the $(R)$-Linezolid (a) and $(S)$-Linezolid (b) molecule and SARS-CoV-2 spike protein (6vW1 - PDB). The isovalue was 0.4 au with a color range of -4.00 to 4.00 , representing attractive, weak and repulsive interactions by the blue, green and red colors respectively



(a)

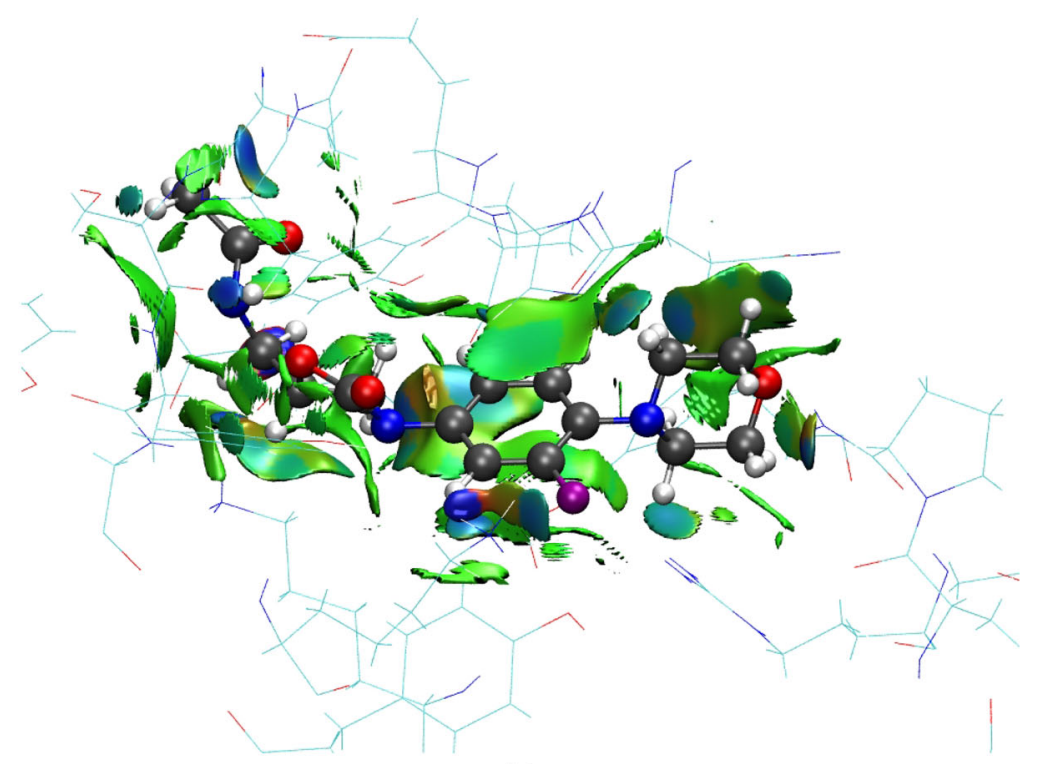

(b) 
The interaction perpendicular to the aryl ring of the Oxazolidone group with HIS-34 of SARS-CoV-2 is highlighted, shown on Fig. 7b. This interactions takes place with the lumo orbitals (Fig.4b), and it is responsible for the attenuation of the UV-Vis signal show on Fig. 3b.

In the NCI calculation for the enantiomer $(R)$-Linezolid, very strong repulsive interactions can be clearly seen, Fig. $8 \mathrm{a}$, as red volumes around the molecule. These strong repulsive interactions, arising from the steric crowding, are evidence for the reason why the $R$ enantiomer does not interact favorably with the protein. The most strong repulsive interactions are found for the LYS 31, PHE 456, PRO 491, and TYR 489 residues, and all these residues are interacting with the oxazolidinone, aryl and morpholine moieties of the molecule. There are also attractive interactions noticed with the PHE 490, LEU 455, LEU 79, and GLN 76 residues, which interact with the same moieties as the repulsive interactions. Of the attractive interactions seen on the $\mathrm{S}$ enantiomer, none are present for the $R$ enantiomer. The C-5-acyl-amino-methyl $\mathrm{N}$ atom has only weak van der Waals interactions with the PHE 28 residue ring, the $\mathrm{O}$ atom of the oxazolidone moiety has no interactions whatsoever and the fluorine atom shows a small interaction with a non acidic hydrogen of LYS31 residue.

On the other hand, the NCI results for the enantiomer $(S)$ Linezolid, Fig. 8b, show no strong repulsive interactions. Most interactions are of the weak van der Waals type, but there are stronger interactions with the residues ASP 38 and SER 494, and attractive interactions with the residues LYS 403, PRO 389, and HIS 34. The residue ASP 38 interacts with one of the Carbons of the acetamide moiety, while the residue SER 494 has a hydrogen bond type interaction with the hydrogen bonded to the nitrogen of the acetamide group. Also, the hydrogen atoms bonded to the terminal amino part of the residue LYS 403 interact with the fluoro atom of the ligand. The other attractive interactions are made with both sides of the rings of the ligand molecule as previously shown.

\section{Conclusion}

Molecular docking of the system (S)-Linezolid $\cdots$ RBD $\cdots$ ACE2 and $(R)$-Linezolid $\cdots$ RBD $\cdots$ ACE2 were performed, showing that only the $(S)$-Linesolid complexes are stable. The stability was indicated by a binding interaction of $-8.05 \mathrm{kcal}^{\mathrm{mol}}{ }^{-1}$ to $(S)$-Linizolid SARS$\mathrm{CoV}-2$ protein interaction compared to $+69.6 \mathrm{kcal}^{\mathrm{mol}}{ }^{-1}$ for the more stable conformation of $(R)$-Linezolid with SARSCov-2 protein. Molecular interactions of $(S)$-Linezolid with SARS-CoV-2 spike protein were analysed by non-convalent interactions, and it was able to show attractive, weak van der Waals and repulsive interactions and the general strength of these forces. The $(S)$-Linezolid has an interaction between the Fluorine and HIS-34 of SARS-CoV-2 protein that is perpendicular to the Oxazolidone ring. Such interactions influence the UV-Vis signal, and it is attenuated in comparison to the isolated species. Interactions of $(S)$ )Linezolid with SARS-CoV-2 spike protein were compare with a well-known system of $(S)$ )-Linezolid complexed with $H$. marismortui ribosome, and the similar interactions presented on both of them suggest the stability and possible activity of $(S)$-Linezolid on SARS-CoV-2 protein.

Supplementary information The online version contains supplementary material available at https://doi.org/10.1007/s00894-021-04828-8.

Author contribution G.S.G., M.I.Y., and S.B. analyzed data and performed research.

M.I.Y., C.M.P., and L.C.S. performed experiments and assisted with figures.

N.H.M. and A.R.S. designed research and analyze data.

C.M.P., L.C.S., M.I.Y, N.H.M, S.B., and A.R.S wrote the manuscript.

Funding This work was supported by the Foundation of the State of Sâo Paulo (FAPESP, grants 2013/08293-7 and 2015/22338-9) and the National Council for Scientific and Technological Development (CNPq, grants 303581/2018-2 and 305541/2017-0). SB acknowledge the University Grants Commission (UGC), Govt. of India for No. F. 4-5/2018 (FRP-Start-up-Grant) (Cycle-IV) (BSR).

\section{References}

1. Ghosh A, Chakraborty M, Chandra A, Alam M (2021) J Mol Model 27

2. Khan S, Fakhar Z, Ahmad A (2021) J Mol Model 27

3. Alazmi M, Motwalli O (2020) J Mol Model 26

4. Vargas G, Geraldo LHM, Salomão NG, Paes MV, Lima FRS, Gomes FCA (2020) Brain, Behavior, \& Immunity - Health 7:100127

5. Gao Y, Wang R, Lai L (2004) J Mol Model 10:44-54

6. Singh K, Kirubakaran P, Nagarajan S, Sakkiah S, Muthusamy K, Velmurgan D, Jeyakanthan J (2012) J Mol Model 18:39-51

7. Schulz-Gasch T, Stahl M (2003) J Mol Model 9:47-57

8. Alsalme A, Pooventhiran T, Al-Zaqri N, Rao D, Rao S, Thomas R (2020) J Mol Model 26

9. Jha R, Khan R, Amera G, Singh E, Pathak A, Jain M, Muthukumaran J, Singh A (2020) J Mol Model 26

10. WHO Coronavirus Disease (COVID-19) Dashboard (2020) 06 September 2020

11. Sanders JM, Monogue ML, Jodlowski TZ, Cutrell JB (2020) JAMA 323:1824-1836

12. Bensikaddour H, Fa N, Burton I, Deleu M, Lins L, Schanck A, Brasseur R, Dufrêne YF, Goormaghtigh E, Mingeot-Leclercq M-P (2008) Biophys J 94:3035-3046

13. Xu Z, Shi L, Wang Y, Zhang J, Huang L, Zhang C, Liu S, Zhao P, Liu H, Zhu L, Tai Y, Bai C, Gao T, Song J, Xia P, Dong J, Zhao J, Wang F-S (2020) The Lancet Respirat Med 8:420422

14. Li F, Cai J, Dong N (2020) J Heart Lung Transplant 39:496-497

15. Elfiky AA (2020) Life Sci 253:117592 
16. Grein J, Ohmagari N, Shin D, Diaz G, Asperges E, Castagna A, Feldt T, Green G, Green ML, Lescure F-X, Nicastri E, Oda R, Yo K, Quiros-Roldan E, Studemeister A, Redinski J, Ahmed S, Bernett J, Chelliah D, Chen D, Chihara S, Cohen SH, Cunningham J, Monforte AD, Ismail S, Kato H, Lapadula G, L'Her E, Maeno T, Majumder S, Massari M, Mora-Rillo M, Mutoh Y, Nguyen D, Verweij E, Zoufaly A, Osinusi AO, DeZure A, Zhao Y, Zhong L, Chokkalingam A, Elboudwarej E, Telep L, Timbs L, Henne I, Sellers S, Cao H, Tan SK, Winterbourne L, Desai P, Mera R, Gaggar A, Myers RP, Brainard DM, Childs R, Flanigan T (2020) New England J Med 382:2327-2336

17. Tobaiqy M, Qashqary M, Al-Dahery S, Mujallad A, Hershan A, Kamal M, Helmi N (2020) Infect Prevent Pract 2:100061

18. Kokic G, Hillen HS, Tegunov D, Dienemann C, Seitz F, Schmitzova J, Farnung L, Siewert A, Höbartner C, Cramer P (2021) Nat Commun, 12

19. Amaro RE, Baudry J, Chodera J, Özlem D, McCammon JA, Miao Y, Smith JC (2018) Biophys J 114:2271-2278

20. Waingeh VF, Groves AT, Eberle JA (2013) Open J Biophys 03:285-290

21. Vakser IA (2014) Biophys J 107:1785-1793

22. Squeglia F, Romano M, Ruggiero A, Maga G, Berisio R (2020) Frontiers in Chemistry 8

23. Mariappan V, Rao R. S., Pillai AB (2020) IUBMB Life 72:25332545

24. Romano M, Ruggiero A, Squeglia F, Maga G, Berisio R (2020) Cells 9:1267

25. Getahun H, Smith I, Trivedi K, Paulin S, Balkhy HH (2020) Bull World Health Organ 98:442-442A

26. Huang B, Ling R, Cheng Y, Wen J, Dai Y, Huang W, Zhang S, Lu X, Luo Y, Jiang Y-Z (2020) Molec Therap - Meth Clinic Develop $18: 367-375$

27. Sagaama A, Brandan SA, Issa TB, Issaoui N (2020) Heliyon 6:e04640

28. Jordaan MA, Ebenezer O, Damoyi N, Shapi M (2020) Heliyon 6:e04642

29. Stevens DL, Dotter B, Madaras-Kelly K (2004) Exp Rev AntiInfect Therap 2:51-59

30. Zhu J, Ke K, Xu L, Jin J (2019) J Mol Model 25

31. Sabe V, Tolufashe G, Ibeji C, Maseko S, Govender T, Maguire G, Lamichhane G, Honarparvar B, Kruger H (2019) J Mol Model 25

32. Zurenko G (2001) Curr Opin Pharmacol 1:470-476

33. Grimme S, Ehrlich S, Goerigk L (2011) J Comput Chem 32:1456-1465

34. Ippolito JA, Kanyo ZF, Wang D, Franceschi FJ, Moore PB, Steitz TA, Duffy EM (2008) J Med Chem 51:3353-3356
35. Sousa I, Heerdt G, Ximenes V, de Souza A, Morgon NH (2020) J Braz Chem Soc 31:613-618

36. Frisch MJ, Trucks GW, Schlegel HB, Scuseria GE, Robb MA, Cheeseman JR, Scalmani G, Barone V, Mennucci B, Petersson GA, Nakatsuji H, Caricato M, Li X, Hratchian HP, Izmaylov AF, Bloino J, Zheng G, Sonnenberg JL, Hada M, Ehara M, Toyota K, Fukuda R, Hasegawa J, Ishida M, Nakajima T, Honda Y, Kitao O, Nakai H, Vreven T, Montgomery JA Jr, Peralta JE, Ogliaro F, Bearpark M, Heyd JJ, Brothers E, Kudin KN, Staroverov VN, Kobayashi R, Normand J, Raghavachari K, Rendell A, Burant JC, Iyengar SS, Tomasi J, Cossi M, Rega N, Millam NJ, Klene M, Knox JE, Cross JB, Bakken V, Adamo C, Jaramillo J, Gomperts R, Stratmann RE, Yazyev O, Austin AJ, Cammi R, Pomelli C, Ochterski JW, Martin RL, Morokuma K, Zakrzewski VG, Voth G, Salvador P, Dannenberg JJ, Dapprich S, Daniels AD, Farkas O, Foresman JB, Ortiz JV, Cioslowski J, Fox DJ (2016) Gaussian 16 (Revision A.03)

37. Dennington R, Keith T, Millam J (2009) GaussView Version 5.0

38. Kim S, Chen J, Cheng T, Gindulyte A, He J, He S, Li Q, Shoemaker BA, Thiessen PA, Yu B, Zaslavsky L, Zhang J, Bolton EE (2018) Nucleic Acids Res 47:D1102-D1109

39. Berman H, Henrick K, Nakamura H (2003) Nat Struct Molec Biol 10:980-980

40. Ahmed SF, Quadeer AA, McKay MR (2020) Viruses 12:254

41. Shang J, Ye G, Shi K, Wan Y, Luo C, Aihara H, Geng Q, Auerbach A, Li F (2020) Nature 581:221-224

42. Morris GM, Huey R, Lindstrom W, Sanner MF, Belew RK, Goodsell DS, Olson AJ (2009) J Comput Chem 30:2785-2791

43. Oferkin IV, Katkova EV, Sulimov AV, Kutov DC, Sobolev SI, Voevodin VV, Sulimov VB (2015) Advances in Bioinformatics 2015:1-12

44. BIOVIA (2019) Dassault Systèmes, BIOVIA Discovery Studio, Release v19

45. Laskowski RA, Swindells MB (2011) J Chem Inf Model 51:2778-2786

46. Johnson ER, Keinan S, Mori-Sańchez P, Contreras-Garciá J, Cohen AJ, Yang W (2010) J Am Chem Soc 132:6498-6506

47. Contreras-García J, Johnson ER, Keinan S, Chaudret R, Piquemal J-P, Beratan DN, Yang W (2011) J Chem Theory Comput 7:625-632

48. Brickner SJ (1996) Oxazolidinone antibacterial agents. In: Chu DTW (ed) Current pharmaceutical design. Bentham Science Publishers, Netherlands

Publisher's note Springer Nature remains neutral with regard to jurisdictional claims in published maps and institutional affiliations. 